\title{
Tamayo, Juan José (2017), Teologías del Sur. El giro descolonizador
}

Antoni Aguiló

\section{OpenEdition}

\section{Journals}

Edición electrónica

URL: http://journals.openedition.org/rccs/8808

DOI: $10.4000 /$ rccs. 8808

ISSN: 2182-7435

Editor

Centro de Estudos Sociais da Universidade de Coimbra

\section{Edición impresa}

Fecha de publicación: 1 mayo 2019

Paginación: 201-203

ISSN: 0254-1106

\section{Referencia electrónica}

Antoni Aguiló, «Tamayo, Juan José (2017), Teologías del Sur. El giro descolonizador », Revista Crítica de Ciências Sociais [En línea], 118 | 2019, Publicado el 26 abril 2019, consultado el 23 septiembre 2020. URL : http://journals.openedition.org/rccs/8808 ; DOI : https://doi.org/10.4000/rccs.8808 


\section{Recensões}

\section{Correia, Pedro de Pezarat (2017), ... da descolonização. Do protonaciona- lismo ao pós-colonialismo. Porto: Book Cover Editora, 830 pp.}

Publicado no final de 2017, este livro do major-general reformado Pedro de Pezarat Correia é em grande parte fruto da tese de doutoramento em Relações Internacionais - Política Internacional e Resolução de Conflitos, que por sua vez recupera algumas das ideias já expostas na longa bibliografia do autor, nomeadamente no livro Descolonização de Angola. A jóia da coroa do império português, de 1992. Oficial de infantaria com seis comissões (na Índia, em Moçambique, em Angola e na Guiné-Bissau), Pezarat descreve o livro como "um mero contributo de um observador que se situava do lado do colonizador" (p. 12). No entanto, o autor não foi um mero observador, pois para além das comissões nos principais teatros de guerra, envolveu-se na contestação ao Congresso dos Combatentes e acompanhou de perto a formação do Movimento dos Capitães em Angola, onde se encontrava em 1974. Depois do golpe militar de 25 de abril foi responsável pela constituição da Comissão Coordenadora do Movimento das Forças Armadas (MFA) em Angola, peça central na evolução da situação política e militar na então província, que à semelhança do que sucedia na metrópole era palco de profundas tensões, fruto de diferentes visões sobre o futuro dos até à data territórios coloniais. É que, como o autor sublinhará, os militares vitoriosos do 25 de Abril apenas estavam unidos num único consenso: o de que a solução para a guerra "teria de ser política e não militar” (p. 242), sendo que a descolonização era "um projeto pouco amadurecido, carente de uma estratégia previamente definida de estudos previsionais com que se depararia" (p. 241). Esta falta de estratégia e a existência de diferentes pontos de vista estaria na origem da aceleração do processo revolucionário em Portugal, que o autor também acompanharia e no qual teria participação ativa na qualidade de membro do Conselho da Revolução e de comandante da Região Militar do Sul.

Por outro lado, apesar de se situar no lado do colonizador, é evidente o esforço que o autor faz para se colocar no lado do "outro", ou seja, do colonizado, procurando valorizar o papel deste como o verdadeiro protagonista em todos os processos de descolonização, apontando o que considera serem "os três vícios de perspetiva com que o ex-colonizador tende a observar o fenómeno da descolonização" (p. 66). São estes a dificuldade do colonizador em compreender que "a descolonização era um processo que o colonizado tinha já posto em marcha”, em "confundir a globalidade da descolonização com a fase da transferência do poder", e em abandonar o "ancestral e etnocêntrico complexo de superioridade" (p. 67).

Dividido em duas partes - a primeira dedicada ao processo de colonização e de descolonização e a segunda centrada no processo de transferência do poder em Angola -, o livro procura oferecer uma perspetiva multidisciplinar em que "a colonização e a descolonização se desenvolveram numa área de interceção do poder e do espaço, da política e da geopolítica, da estratégia e da geoestratégia” (p. 25). 
Assim, a primeira parte começa com um "enquadramento conceptual" que agrupa colonização e descolonização no mesmo fenómeno histórico, o colonialismo, afirmando o autor que "a descolonização nasce com a aspiração de um povo a ser soberano na sua terra ocupada" (p. 21). Esta afirmação merecia um maior desenvolvimento, deixando ao leitor um conjunto de interrogações. Qual o conceito de povo utilizado? Podemos falar da existência de um povo em Angola ou em Moçambique em 1974/1975? Se sim, não são esses povos frutos da colonização portuguesa? É o nacionalismo africano credor da colonização europeia? Devemos considerar que ainda não se verificou uma verdadeira descolonização, pois tanto os movimentos de guerrilha, como a Organização das Nações Unidas (ONU) e a Organização de Unidade Africana (OUA) sempre procuraram garantir a unidade e integridade de cada território colonial e opuseram-se a toda e qualquer tentativa separatista ou a tentativas de desmembramento nos processos de independência, como aliás é recordado na parte do livro dedicada ao problema de Cabinda (pp. 491-509)? Uma plena descolonização não implicaria a destruição dessas construções artificiais, desenhadas a regra e esquadro em 1884/85 na Conferência de Berlim?

$\mathrm{Na}$ primeira parte do livro, o meritório esforço de se colocar do outro lado corre o risco de não ser suficientemente calibrado, sobressaindo uma recorrente utilização de citações de conhecidos ideólogos da luta anticolonialista, que revelam visões dicotómicas onde não há espaço para cambiantes e que, entre outros aspetos, alimentam o mito do bom selvagem. Sendo verdade que a história do colonialismo é uma história de violência, um leitor menos atento pode ficar com a ideia, errada, de que antes da chegada dos europeus não existiam conflitos. Ora, se existem vícios de perspetiva de um lado também existem vícios de perspetiva do outro e ambos devem ser combatidos. Ao referir alguns teóricos do fenómeno da colonização, Pezarat cita um autor que explica o colonialismo como resposta a um problema demográfico. No caso português dificilmente se pode explicar o colonialismo com este fenómeno. Desde os primórdios se ouviram críticas ao impacto negativo da expansão, tendo ficado célebre a frase de Sá de Miranda: "que ao cheiro desta canela/o reino nos despovoa". Por outro lado, as políticas de fixação de colonos nos territórios coloniais foram maioritariamente mal sucedidas e desde o século XIX se verifica que aqueles que procuraram melhores condições de vida fora da metrópole fizeram-no maioritariamente para outros destinos que não as colónias, apesar dos incentivos promovidos pelo Estado português, por exemplo, pelas Juntas Provinciais de Povoamento. ${ }^{1}$ Esta dificuldade em fixar colonos explica o paradoxo que o livro aflora ao relacionar colonização e descolonização. É que ao contrário do sucedido nas colónias de outras potências europeias, o grande surto colonialista da terceira vaga imperial portuguesa dá-se após a Segunda Guerra Mundial, precisamente quando se começa a assistir ao fim dos impérios europeus. Este colonialismo tardio dificultava qualquer tentativa de aproximação às forças independentistas que pouco a pouco foram despontando nos diversos territórios (pp. 103-113), muito embora sem nunca terem conhecido a pujança verificada noutras colónias europeias uma vez que

\footnotetext{
${ }^{1}$ Castelo, Cláudia (2007), Passagens para África: o povoamento de Angola e Moçambique com naturais da metrópole. Porto: Edições Afrontamento.
} 
escasseavam os meios sociais, económicos e culturais mais propícios ao surgimento, desenvolvimento e propagação das ideias independentistas. Como sublinha Pedro Aires Oliveira, o começo da guerra em Angola em 1961 "conferiu um impulso tremendo à expansão do aparato colonial, ao investimento público (e depois privado), ao crescimento e diversificação económica e ao povoamento branco". ${ }^{2}$ Acresce que o Estado Novo era um regime autoritário não fazendo sentido falar-se em direito à autodeterminação dos povos colonizados (p. 123) quando essa mesma autodeterminação era negada aos próprios naturais da metrópole.

Além do mito do bom selvagem, o livro acaba também por involuntariamente exacerbar outro mito, curiosamente alimentado não pelos opositores do Estado Novo mas pelos seus apologistas: o mito do "orgulhosamente sós". Ao longo da obra, são diversas as vezes em que este mito é alimentado. Logo no prefácio refere-se o isolamento externo de Portugal "nas relações Estado a Estado e nas instâncias internacionais da ONU, da OUA e mesmo da OTAN [Organização do Tratado do Atlântico Norte], remetido ao apoio de Estados diplomaticamente marginalizados" (p. 14). No capítulo 4 da primeira parte, volta a referir-se o isolamento internacional, sendo afirmado que "o único aliado fiel e permanente com que contou nesta luta foi a África do Sul e, já na parte final, os EUA [Estados Undidos da América], quando estes inverteram a sua política para a África Austral” (p. 136). Sucede que vários trabalhos de investigação têm revelado o contrário, ou seja, que apesar do aparente isolamento, o Estado Novo pôde contar com importantes apoios de países europeus no seu esforço de guerra, nomeadamente da França e da República Federal da Alemanha. ${ }^{3} \mathrm{O}$ apoio bilateral destes dois importantes países membros da OTAN e a mudança de posição dos EUA após a pressão exercida sobre Portugal no início da presidência Kennedy, garantiram alguma tranquilidade ao regime e permitiram que nas vésperas do 25 de Abril apenas na Guiné-Bissau a situação militar fosse claramente desfavorável a Portugal. Mas, se Portugal contara com apoios externos, também estes foram fundamentais para os guerrilheiros independentistas. Pezarat defende que na Guerra Colonial se cruzaram quatro conflitos: a luta de libertação; o conflito regional; o conflito Leste-Oeste; e a guerra civil (pp. 133-138). Já antes tinha relacionado as guerras de libertação à Guerra Fria e ao mundo bipolar do pós-guerra (pp. 59-64), no entanto, a falta de uma clara hierarquização tende a menosprezar a importância do contexto internacional global, a Guerra Fria, quando todos os outros conflitos estão enquadrados por este e lhe estão subordinados, mesmo que indiretamente.

Nesse sentido, sente-se a falta de um maior enquadramento do processo de criação e desenvolvimento dos movimentos independentistas na lógica da Guerra Fria. A primeira referência ao apoio internacional concedido aos movimentos independentistas surge apenas na página 129 , depois de feita a descrição do nascimento dos vários partidos e movimentos (pp. 104-110),

\footnotetext{
${ }^{2}$ Costa, João Paulo Oliveira e (coord.); Rodrigues, José Damião; Oliveira, Pedro Aires (2014), História da expansão e do império português. Lisboa: A Esfera dos Livros, p. 509.

${ }^{3}$ A este propósito vejam-se os trabalhos de Fonseca, Ana Mónica (2007), A força das armas: o apoio da República Federal da Alemanba ao Estado Novo (1958-1968). Lisboa: Ministério dos Negócios Estrangeiros; de Marcos, Daniel da Silva (2007), Salazar e de Gaulle: a França e a questão colonial portuguesa (1958-1968). Lisboa: Ministério dos Negócios Estrangeiros.
} 
e, novamente, na página 277 , no capítulo dedicado ao início das negociações para a transferência de poderes onde se refere o treino militar de 30 cabo-verdianos feito em Cuba, no ano de 1966. Já o apoio da União das Repúblicas Socialistas Soviéticas (URSS) aos movimentos guerrilheiros durante a Guerra Colonial, apenas é referido quando é abordado o apoio concedido durante a fase das independências: "A URSS reforçou o apoio aos seus aliados de Angola e Moçambique, em continuação do que já havia concedido aos respetivos movimentos de libertação na guerra colonial” (p. 336). Se é verdade que, ao contrário do que difundia o regime autoritário português, Moscovo não foi o único nem o principal patrocinador desses movimentos, não é possível fazer-se uma completa análise da ação dos movimentos, da sua sobrevivência, da Guerra Colonial e da descolonização, sem referir o papel da URSS. O mesmo se pode dizer do papel da outra superpotência, os EUA, mas esse é referido tanto na primeira parte do livro, quando se descrevem as várias démarches diplomáticas empreendidas pelos norte-americanos no sentido de contribuírem para uma mudança na política colonial de Salazar (p. 114), ou quando se descreve a opção Tar Baby e a sua articulação com o Exercício Alcora, ou seja, uma aproximação dos EUA a Portugal, à África do Sul e à Rodésia (p. 120 e pp. 304-311), como na segunda parte, dedicada à transferência do poder em Angola.

Curiosamente, nesta última parte do livro verifica-se também uma certa desvalorização da lógica bipolar. Logo no primeiro capítulo, referindo-se ao apoio de Cuba ao Movimento Popular de Libertação de Angola (MPLA), o autor defende que a intervenção dos cubanos "deve ser interpretada no quadro do conflito regional e não no da guerra-fria", e que se tratou de "uma iniciativa na linha da solidariedade internacionalista, sem qualquer interferência de Moscovo" (p. 394). A sustentar esta tese, surge apenas uma citação de um autor que defende que Cuba não atuou como satélite ou simples peão da URSS, embora reconheça que a operação contou com o apoio logístico de Moscovo (p. 395). Para Pezarat, que reconhece que o apoio de Cuba foi decisivo para a vitória do MPLA, este apenas ocorreu para responder à invasão sul-africana, valorizando assim a lógica do conflito regional em detrimento do conflito mundial. Desta forma, é desvalorizado o papel da URSS, mas ao mesmo tempo sublinhado o papel dos EUA que, de acordo com o autor, através da Central Intelligence Agency (CIA) coordenavam "as forças combinadas da FNLA, UNITA, FLEC, SADF, zairenses, mercenários portugueses" (p. 395). Sucede que a ação de Cuba e a sua própria existência não se consegue compreender sem a devida contextualização na Guerra Fria, do mesmo modo que o tardio processo de colonização/descolonização português não pode ser entendido fora do quadro bipolar nascido no pós-guerra.

É esse enquadramento que explica como é que Portugal conseguiu suportar durante tantos anos uma guerra em três cenários distintos, que ao mesmo tempo conheceram um acelerado processo de desenvolvimento. É esse enquadramento que decifra o rumo dos acontecimentos na metrópole após o 25 de Abril e é também esse enquadramento que condiciona o processo que conduziu às independências das antigas colónias portuguesas.

Esta obra de Pedro de Pezarat Correia ajuda a compreender esse processo e constitui uma mais-valia para todos aqueles que pretendem conhecer melhor o modo de pensar e de agir dos militares que a guerra levou a progressivamente se identificarem com o adversário.

David Castaño 


\section{Pereira, Bernardo Futscher (2017), Crepúsculo do colonialismo: a diplo- macia do Estado Novo (1949-1961). Alfragide: Publicações Dom Quixote, 312 pp.}

A história diplomática e transnacional, campos tradicionalmente marginalizados na historiografia produzida em espaços académicos de língua oficial portuguesa, têm nos últimos anos sofrido um processo de notável crescimento e renovação. Vários são os artigos, teses de doutoramento, monografias e volumes publicados nestas áreas, e não seria um exagero afirmar que o que de mais fascinante se tem escrito recentemente compartilha uma perspectiva que poderia ser sumariamente descrita como histórias que vão "além da nação". Por esta expressão quer-se aqui referir a um modo de narração histórica em que o Estado-nação já não assume a centralidade absoluta ou figura como ator monolítico. Nesta tentativa de superar "a nação" como um quadro conceptual e epistemológico limitador, historiadores têm cada vez mais se interessado em explorar o "internacional" como um terreno produtivo, como uma lente que nos ajuda a melhor perceber a complexidade dos processos históricos, que um olhar estritamente nacional (ou nacionalista) poderá ter obscurecido. Aqui, os temas da descolonização e do colonialismo tardio têm sido particularmente sujeitos a novas e fascinantes leituras.

Do ponto de vista do historiador ou cientista social, o livro aqui em apreço pode ser lido em relação a este universo historiográfico mais amplo, ainda que o Bernardo Futscher Pereira, infelizmente, não dialogue de forma consistente com alguns dos títulos de maior relevo na literatura académica especializada, um ponto ao qual voltarei abaixo. Crepúsculo do colonialismo, no entanto, talvez seja apresentado mais efetivamente não como um título académico per se, mas antes como uma narrativa ensaística, cujo evidente valor intelectual e fundamentos investigativos por certo despertarão o interesse tanto do mundo académico quanto do público leigo em geral. Escrito numa prosa de fácil acesso e permeado por anedotas curiosas e interessantes, o livro é bastante versátil na forma e conteúdo. Isto talvez possa ser explicado, pelo menos parcialmente, pela trajetória pessoal e profissional do próprio autor, que inclui a formação académica em Ciências Políticas e Relações Internacionais, o trabalho como jornalista e, mais tarde, como diplomata. Estes posicionamentos profissionais distintos fazem-se sentir nas escolhas narrativas e complementam-se de forma interessante ao longo do livro, em benefício do produto final. O autor, que conta com a experiência bem sucedida de ter publicado, em 2012, o título A diplomacia de Salazar (1932-1949), pela mesma editora, agora nos oferece um outro livro que funciona como o seguimento natural deste. ${ }^{1}$

Como o subtítulo sugere, o livro examina a política diplomática do Estado Novo no período pós-guerra até ao explodir da resistência anticolonial armada em África e da perda da então chamada Índia Portuguesa, ambos eventos profundamente marcantes que fazem de 1961 um divisor de águas por excelência na

\footnotetext{
${ }^{1}$ Pereira, Bernardo Futscher (2012), A diplomacia de Salazar: 1932-1949. Lisboa: Publicações Dom Quixote.
} 
cronologia da descolonização portuguesa. A expressão que dá título ao livro - crepúsculo do colonialismo -, criativamente emprestada de um documento diplomático, enviado da Embaixada de Portugal em Londres ao Ministério dos Negócios Estrangeiros em meados dos anos 1950, evidencia que o patente declínio do colonialismo europeu assumia nos círculos políticos e diplomáticos portugueses um sentido de imensa centralidade e urgência que não se podia ignorar. O livro convincentemente prossegue com uma análise minuciosa das decisões políticas e estratégias diplomáticas empregadas de maneira a enfrentar e impedir o fim do colonialismo como um processo global, e não apenas como algo relativo a Portugal isoladamente. A esta análise política e diplomática propriamente dita, o autor acrescenta comentários inusitados sobre a disposição pessoal de figuras de relevo, de diplomatas de carreira em altos cargos, de Ministros dos Negócios Estrangeiros e do próprio Presidente do Conselho. Estas curiosas incursões pelas mentes nem sempre concordantes de Adriano Moreira, António Salazar, Vasco Garin, Franco Nogueira, entre outros, dão-nos algumas pistas sobre as diferentes perspectivas políticas, institucionais e pessoais que coexistiam dentro da própria "diplomacia do Estado Novo", que permanece ao longo do livro como um campo de tensão e não como um conjunto monolítico de diretivas rigidamente definidas por um centro de poder.

Outro benefício do livro é a sua amplitude temática e geográfica. Embora o autor não busque expressamente apresentar uma história total da diplomacia do Estado Novo (o que seria impossível, sobretudo numa obra de menos de 300 páginas), também não limita o seu horizonte analítico e narrativo a cortes conceptuais preconcebidos e a debates convencionais. Há uma tendência na literatura académica para responder e inserir-se num campo de estudo específico. O historiador, neste sentido, é encorajado a narrar uma história bem-acabada que intervenha num debate sobre, por exemplo, a Guerra Fria ou as relações luso-americanas, sobre o papel de organismos internacionais ou sobre o desenrolar da descolonização em países ou regiões específicos, etc. É mais raro encontrarmos um estudo que consiga, de maneira convincente, articular diversos temas e espaços geográficos em redor de uma narrativa comum. Crepúsculo do colonialismo procede desta forma e com sucesso. Temos aqui uma história da descolonização que começa em Macau nos anos 1940 e termina com a ocupação militar do Estado Português da Índia pelo exército indiano em 1961. Ao longo de cinco capítulos organizados em três partes, Bernardo Futscher Pereira trata de temas tão diversos como a formação estratégica da Organização do Tratado do Atlântico Norte, a adesão de Portugal à Organização das Nações Unidas (ONU), a aproximação diplomática de Portugal ao Brasil e à África do Sul, o deteriorar das relações luso-indianas, a importância da religião e das relações com a Santa Sé na diplomacia portuguesa, as respostas de Lisboa aos desafios que se avizinhavam com a emergência do chamado Terceiro Mundo, as vozes críticas e dissonantes que se apresentavam dentro do próprio Estado Novo, até à emergência da violência anticolonial em Angola. É nesta abordagem multitemática e geograficamente multifocal que a contribuição deste livro reside. Este modelo narrativo permite-nos perceber que eventos pouco explorados na história do colonialismo português, tais como, por exemplo, a Crise do Congo, viriam a ter um papel importante em condicionar os argumentos e estratégias disponíveis à diplomacia do Estado Novo em espaços internacionais. 
Embora o próprio autor reconheça que o estudo se constrói como uma revisão da literatura existente e, portanto, baseia-se sobretudo em fontes secundárias, ele não deixa de incluir fontes primárias, buscadas no Arquivo Histórico-Diplomático ou em publicações oficiais do Ministério dos Negócios Estrangeiros. Ainda assim, há um certo desequilíbrio no uso da documentação: as secções relativas às questões do Estado Português da Índia e da diplomacia portuguesa na ONU estão melhor fundamentadas em fontes primárias do que as demais. Esta atenção minuciosa às relações luso-indianas pode talvez ser relacionada com o facto de o autor ser casado com uma historiadora deste tema, Maria Manuel Stocker, autora de Xeque-mate a Goa, um importante título amplamente citado ao longo do livro. ${ }^{2}$ Para frustração de historiadores profissionais, parte das fontes primárias citadas na obra não trazem consigo a sua referência arquivística, o que dificultará a sua consulta e utilização em futuros estudos. O livro poderia também beneficiar de um diálogo mais consistente com a literatura recentemente produzida. Não faz referência aos estudos publicados, por exemplo, por Jerry Dávila, Maria Paula Meneses e Bruno Sena Martins, Miguel Bandeira Jerónimo e José Pedro Monteiro, e Aurora Almada e Santos. ${ }^{3}$ Claro está, isto é menos uma deficiência do livro em si, e mais um testemunho da imensa produtividade académica e editorial nos campos da história diplomática e transnacional, de que o livro em apreço é mais uma interessante contribuição.

Caio Simões de Araújo

\section{Tamayo, Juan José (2017), Teologías del Sur. El giro descolonizador. Madrid: Trotta, 252 pp.}

El último libro de Juan José Tamayo, uno de los teólogos críticos más relevantes del panorama actual, comienza con una declaración de intenciones introductoria imprescindible para entender el giro copernicano que viene operándose en el autor ya desde obras anteriores como Nuevo paradigma teológico (2009), Fundamentalismos y diálogo entre religiones (2009) y Otra teología es posible.
Pluralismo religioso, interculturalidad y feminismo (2012). Tamayo adopta sistemáticamente la perspectiva descolonial como referente epistemológico a partir del cual contribuye a un "cambio de paradigma en el relato teológico" capaz de sentar las bases de una teología poscolonial e intercultural en diálogo con las llamadas "teologías emergentes" del Sur global (p. 11). De este modo, el libro aborda

\footnotetext{
2 Stocker, Maria Manuel (2011), Xeque-mate a Goa. Alfragide: Texto Editores.

3 Dávilla, Jerry (2012), Hotel Trópico: Brazil and the Challenge of African Decolonization. Durham: Duke University Press; Meneses, Maria Paula; Martins, Bruno Sena (orgs.) (2013), As guerras de libertação e os sonhos coloniais: alianças secretas, mapas imaginados. Coimbra: CES/Almedina; Jerónimo, Miguel Bandeira; Monteiro, José Pedro (orgs.) (2015), Os passados do presente: internacionalismo, imperialismo e a construção do mundo contemporâneo. Coimbra: Edições Almedina; Santos, Aurora Almada e (2017), A Organização das Nações Unidas e a questão colonial portuguesa: 1960-1974. Lisboa: Instituto da Defesa Nacional.
} 
las ideas principales, las metodologías y los autores clave involucrados en el surgimiento y el desarrollo de estas diversas corrientes, así como su relevancia para un cambio de rumbo en la teología.

Las ideas centrales de la obra son la reivindicación de la riqueza de los pluriversos religiosos y teológicos que emergen en el Sur global y la necesidad de construir, en la línea de la epistemología del Sur que propone Boaventura de Sousa Santos, teologías que promuevan ecologías de saberes y de prácticas de emancipación, es decir, conscientes del carácter inacabado de todos los enfoques y de la necesidad de tender puentes entre diferentes voces para enfrentar colectivamente los sistemas de dominación.

El Sur global se concibe como un campo heterogéneo de creatividad e innovación caracterizado por una pluralidad de discursos teológicos transgresores de los sistemas de dominación que denuncian la colonialidad constitutiva de la teología eurocéntrica, desarrollan nuevos lugares de enunciación teológica y amplían el repertorio de temas y sujetos teológicos (negros, mujeres, campesinos, pueblos indígenas, LGTBI, la Madre Tierra, etc.), incorporando la intersección entre diferentes categorías de análisis, como género, clase, etnia o sexualidad. Ejemplos de ello son las teologías africanas, asiáticas y latinoamericanas de la liberación, las teologías afroamericanas y caribeñas, las teologías indígenas, las teologías feministas y las teologías LGTBI.

A lo largo de los siete capítulos que lo componen, el libro se articula en torno a dos grandes ejes temáticos relacionados: la crítica de las religiones que ejercen su hegemonía sobre otras tradiciones religiosas y las teologías contrahegemónicas emergentes en el Sur global que optan por la descolonización del conocimiento teológico y de sus formas de producción, dando lugar a nuevos discursos y prácticas de carácter emancipador.

Respecto al primer eje, Tamayo analiza seis paradigmas religioso-epistemológicos dominantes cuya imposición empobreció la diversidad y la heterogeneidad de la experiencia religiosa: el giro monoteísta, el paradigma católico-romano medieval y el cristianismo colonial en América Latina, África y Asia. Estas hegemonías religiosas han producido mecanismos de represión. Tamayo muestra cómo el surgimiento y la difusión del monoteísmo cristiano condujo a reclamos de lo absoluto que se tradujeron militar y políticamente e hicieron que el cristianismo colonial no pudiese dialogar sobre la riqueza de otras religiones.

El segundo eje aborda los cambios teológicos en dirección al pluralismo producidos en la teología cristiana occidental entre mediados del siglo XIX y el siglo XX. La interpretación se abre a nuevos horizontes de carácter cada vez más intercultural, interreligioso, feminista, práctico-ético, ecológico, anamnético (en el sentido de recuerdo de las víctimas y excluidos), utópico, simbólico, económico-político y descolonial. Los elementos básicos de esta apertura son la percepción y el significado del otro en su alteridad. Posteriormente el autor ofrece una caracterización detallada de las teologías emergentes y poscoloniales. En lo que se refiere a las teologías africanas, Tamayo examina el impacto del cristianismo como religión imperial, así como las principales tendencias de las teologías cristianas negras, vividas desde una contextualidad en la que los conceptos de liberación (por ejemplo, contra el apartheid), la inclusión de las mujeres y la inclusión de las religiones ancestrales desempeñan un papel esencial. Tamayo entra en detalles sobre la teología basada en la filosofía ubuntu del pueblo bantú. Esta tradición se caracteriza por una interdependencia basada en el ser con 
la hospitalidad, la empatía y la naturalidad de colaborar y compartir.

La teología negra estadounidense también cuenta con su propio capítulo. Tamayo rastrea su evolución desde la década de 1960 hasta la de 1980. Se originó en Estados Unidos en el contexto del racismo antinegro. Martin Luther King en el lado cristiano y Malcolm X en el islámico se convirtieron en un desafío inequívoco para la transformación de la sociedad estadounidense en términos de igualdad y justicia. Posteriormente Tamayo se ocupa de las tendencias actuales de esta corriente. Una mirada a Asia también revela la diversidad de tradiciones religiosas allí presente, reconocida por el Congreso de la Asociación Ecuménica de Teólogos del Tercer Mundo en Sri Lanka en 1979. Tamayo se aproxima a la teología de la liberación en su variante islámica, hindú, budista, confucionista, judía y palestina, sobre las cuales la teología de la liberación latinoamericana ejerció notable influencia. Solo por nombrar algunos: en la India, Asghar Ali Engineer, en el sur de Asia, Aloysius B. Chang, en el lado judío, pero con la mirada puesta sobre Palestina, Marc H. Ellis y Naim Stifan Ateek. Teólogos cristianos de Asia como Aloysius Pieris, Michael Amaladoss, Kwok Pui-Lan y Hyun Kyung Chung muestran cómo sus conceptos involucran deliberadamente cuestiones como la secularización, las cuestiones de género o la religión ancestral. El recorrido de Tamayo por las teologías del Sur prosigue por la teología latinoamericana de la liberación. Esta tendencia ha recibido un nuevo ímpetu con el papado de Francisco. Era y es una teología bajo premisas éticas basadas en la opción por los pobres, lo que llevó a los teólogos de la liberación a participar deliberadamente en análisis del marxismo. Entre las nuevas tendencias se encuentran la teología feminista negra de América Latina y el Caribe, que toma elementos cultuales del candomblé, la santería y el lumbalú, así como la ecoteología y la teología queer, entre otras corrientes.

El último capítulo está dedicado a la teología indígena de la región andina, articulada sobre el principio de sumak kawsay (buen vivir): "Una cosmovisión, una ética, un estilo de vida y un modo de relación armónica de las comunidades indígenas con la naturaleza, el cosmos, los ancestros, los hermanos y hermanas de las comunidades y todos los seres humanos" (p. 215). En un mundo globalizado y neoliberal, los pueblos indígenas se están convirtiendo cada vez más en una reserva crítica de fuerza gracias a su comprensión holística de la vida.

Estamos, en síntesis, ante una estimulante y necesaria propuesta de renovación epistemológica de la teología en clave descolonial, que se alinea con los saberes y las luchas que trabajan contra el heteropatriarcado, el neocolonialismo, el imperialismo, la mercantilización capitalista de la vida, el racismo, la destrucción ecológica, la crisis de la democracia y los fundamentalismos de cualquier tipo. Una renovación que apunta a un horizonte de pensamiento teológico transformador que articula teología y liberación y que se basa en la defensa de la dignidad ecohumana, la solidaridad y la justicia social y epistémica en la perspectiva de búsqueda del ecumenismo, el pluralismo y el diálogo intercultural e interreligioso.

Antoni Aguiló 


\section{Reis, José (2018), Economia portuguesa: formas de economia política numa periferia persistente (1960-2017). Coimbra: Edições Almedina, 274 pp.}

\section{Portugal: renovada condição de periferia}

O livro de José Reis é uma densa e cuidadosa análise sobre a economia portuguesa do período entre 1960 e 2017, que reflete o acúmulo da sua trajetória de investigador científico e de gestor público. Para os leitores não familiarizados com temas sobre a organização e a evolução dos sistemas econômicos, as dinâmicas produtivas, o trabalho e os sistemas de emprego, as formas de relacionamento supranacional, a governação da economia em período autoritário, democrático e de economia da austeridade, o livro é um convite a uma leitura didática e esclarecedora, sem perder o rigor acadêmico-científico.

A obra está organizada em cinco capítulos. Apresenta - a partir do domínio da economia política - elementos conceituais, históricos e indicadores da economia portuguesa, de forma a compreender a sua condição de periferia, a economia política do empobrecimento, a sobredeterminação institucional da União Europeia (UE), a prolongada estagnação na sequência da adesão à União Económica e Monetária (UEM) e os problemas e possibilidades de uma economia política de recuperação a partir de 2015. Ou seja, o livro faz uma revisão dos ciclos econômicos após o longo período de Portugal enquanto país colonizador "anacrônico", como caracteriza o autor.

Ao longo dos capítulos, Reis trata de evidenciar os fundamentos para situar Portugal como uma periferia na Europa. O período de industrialização (1960-1974) revelou a incapacidade de se modernizar, de qualificar o sistema produtivo e o mercado de trabalho. Para o autor, Portugal tem uma originalidade inescapável: instalou um setor industrial pesado e moderno, com elevados volumes de capital fixo enquanto fez do trabalho a sua principal mercadoria de exportação. O “regresso" à democracia (1975-1983) deu prioridade aos mecanismos de estruturação interna e à economia política da democracia. Depois da Revolução dos Cravos, a principal decisão foi a de democratizar e possibilitar que o acesso ao bem-estar se generalizasse por meio das políticas econômicas e de grandes transformações institucionais, com vista à redução das desigualdades e à reorganização da estrutura econômica. Deu-se prioridade a processos de modernização empresarial e adequou-se a esfera pública, cultivando um ambiente de europeização. O período de 1984-1992 foi, em parte, a continuidade da economia política da democracia, mas aliado à reorganização da economia e da sociedade até à integração monetária, destacando-se pelas reformas das instituições, com privatizações, proteção a grupos econômicos e liberalização do mercado de trabalho.

A preparação para a integração na UEM (1993-2003) se fez pelos mercados, instalando o "poder burocrático europeu, criador de regras e de instituições destinadas a condicionar e reduzir a esfera pública" (p. 6). A arquitetura institucional da UEM adotou o processo de financeirização construída no plano internacional. Os tratados e pactos foram "mostrando que estava desfeita a relação de redistribuição entre crescimento, pleno emprego e desenvolvimento dos sistemas de redistribuição com aumento dos salários” (p. 61). Em Portugal, a economia tornou-se profundamente dependente do exterior e sua posição de devedor foi acelerada, intensificou-se 
a fragilidade da sociedade e da economia e se renovou a condição de periferia. $\mathrm{O}$ novo quadro institucional da UEM (2003-2015) reduziu o espaço das políticas públicas e protegeu as relações de mercado, subjugando o financiamento público e a política monetária de cada país. Portugal entrou numa tendência de estagnação e, em 2011, adotou o programa de política econômica do Memorando de Entendimento assinado com a União Europeia, o Fundo Monetário Internacional e o Banco Mundial (troika), que o autor denominou de economia política da austeridade. Esta é "recessiva e deflacionária, dá primazia aos valores financeiros, contrai os rendimentos salariais, produz uma forte reconfiguração social e económica, com retrocesso de direitos e de formas de proteção social, hostiliza o Estado e a esfera pública, promove a conflitualidade, 'naturaliza' a arquitetura institucional que ela própria criou e enaltece o individualismo" (pp. 67-68). Ao proteger os setores onde estão os capitais mais poderosos, a economia portuguesa se desligou de si própria e da sociedade, tendo esta arcado com os custos. Tratou-se da "mais forte captura recessiva da economia [...] em favor de uma reversão das relações sociais, especialmente das laborais, e do papel do Estado" (p. 73). A política de austeridade causou um choque violento à economia e à sociedade portuguesa, mas uma viragem política relevante ocorreu em 2015 - com a formação de um governo socialista com apoio parlamentar de outros partidos à esquerda -, na qual se ensaia uma reação da mudança da economia política por deliberação democrática. "Não se tendo alterado as condições institucionais, nem as restrições principais, seja no plano europeu, seja no plano internacional em geral, o que esta nova fase significa é que é possível agir politicamente dentro das capacidades que um país possui" (p. 70).
A defesa de algumas posições político-econômicas traduzem o pensamento e a preocupação do autor. Portugal escolheu um modelo de desenvolvimento que não gera empregos de qualidade e fica, portanto, sujeito a determinações da macroeconomia advindas do ingresso na UE, que redefiniu sua economia e sua sociedade. Estes são temas abordados ao longo dos cinco capítulos, a princípio historicamente e, em seguida, com análise de indicadores econômicos, clareando os motivos a respeito do não crescimento da economia portuguesa e a sua dependência significativa do contexto europeu. Para compreender outra determinante do empobrecimento português, o autor faz uma análise especial da arquitetura da UE, que estabelece a vitória liberal e conservadora do mercado sobre quaisquer outros interesses, deixando que economias diferentes sejam submetidas a critérios que desconsideram seu grau diferenciado de desenvolvimento. Por fim, sintetiza: a UEM é um verdadeiro "governo da Banca” (p. 187), que privilegia a financeirização da economia e é "uma insensata carta de condicionalidades e um mecanismo gerador de constrangimentos" (p. 185) para os países periféricos.

No conjunto, a avaliação do autor é que os ciclos da evolução econômica de Portugal são instáveis, com desequilíbrios sistemáticos, dependência persistente e onde o poder para controlar a evolução econômica e social é baixo. Estes ciclos foram apresentados e analisados de forma a compreender a industrialização, a desruralização e a terceirização nas dimensões da produção, do emprego, da geração e redistribuição de rendimento e da provisão de bem-estar. Esta leitura - que está longe de ser uma contabilidade do crescimento - evidencia a dimensão limitada desse crescimento em cada período, os escassos efeitos de uma economia que não tem repercussões 
essenciais no emprego e no mercado de trabalho, e por essas razões, incapaz de estruturar um processo de crescimento e forjar possibilidades de democracia política e de democracia econômica. Determinando o retrato de Portugal na segunda década dos anos 2000: um país que desenvolveu um turismo de massas, serviços generalistas e trabalho precário e mal remunerado, tendo-se tornado a terceirização excessiva com um uso extensivo de trabalho sem criação de valor.

O professor José Reis merece ser lido por todos, europeus - portugueses especialmente - mas também por leitores de outros países e, em particular, brasileiros, de modo a observar: primeiro, a importância da análise econômica através do prisma da economia política observando aspectos sociais e políticos, relevantes nas escolhas; segundo, a elaboração de uma metodologia de análise considerando os momentos históricos econômico-políticos, que ajudam a compreender o presente; e, por último, a ênfase na financeirização do capital e, por consequência, das atividades econômicas, com reflexos em todas as relações sociais. Por fim, este é um livro perpassado pela emoção do autor e pelo desejo de que seu país cumpra as finalidades que ele entende como precípuas: os destinatários do desenvolvimento econômico serem as pessoas e a sociedade, a inserção pelo trabalho ser o mais poderoso mecanismo de inclusão na contemporaneidade, que a economia satisfaça as condições da democracia e que o Estado tenha centralidade na ação pública.

\section{Tânia Regina Krüger Edyvar de Mattos Guimarães}

\section{Ferro, Lígia; Smagacz-Poziemska, Marta; Gómez, M. Victoria; Kurtenbach, Sebastian; Pereira, Patrícia; Villalón, Juan José (orgs.) (2018), Moving Cities - Contested Views on Urban Life. Wiesbaden: Springer VS, 223 pp."}

É impossível pensar o mundo contemporâneo sem pensar nas nossas cidades e nas várias questões que as caraterizam. Nomeadamente as várias visões contestadas e contraditórias que compõem a Sociologia Urbana. Esse é o grande objetivo do livro Moving Cities - Contested Views on Urban Life de 2018, organizado por Lígia Ferro, Marta Smagacz-Poziemska, M. Victoria Gómez, Sebastian Kurtenbach, Patrícia Pereira e Juan José Villalón. Com este livro, os autores (a maioria investigadores na European Sociological Association Research Network 37 - Urban Sociology) e os organizadores pretendem trazer novas e diferentes visões sobre as cidades e a vida urbana, usando exemplos de várias cidades da Europa, mas também dos Estados Unidos da América e do Brasil. Ao longo de 12 capítulos, são dadas a conhecer diversas visões sobre as questões urbanas mais relevantes dos nossos tempos, acabando estas por terem, muitas vezes, pontos em comum, embora retratando questões diferentes.

\footnotetext{
* Este texto foi realizado no âmbito de uma Bolsa de Doutoramento da Fundação para a Ciência e a Tecnologia (ref. ${ }^{a}$ SFRH/BD/137480/2018), financiada pelo Fundo Social Europeu e por fundos nacionais do Ministério de Ciência, Tecnologia e Ensino Superior de Portugal.
} 
As cidades, apesar de globais, tornaram-se locais de conflitos e contradições, mas igualmente locais de reivindicação de direitos, seja por parte de integrantes das classes baixas ou do poder financeiro global. Assim sendo, não é possível pensar numa única forma de cidadania, mas sim em várias (capítulo 1, de Saskia Sassen). Além da reivindicação de direitos, também não estamos estáveis num único local, mas em constante mobilidade no interior das cidades, obrigando a uma nova reconfiguração da ideia de "comunidade", passando-se a falar em "comunidades", formadas por pessoas das mais diversas origens sociais (capítulo 2, de Talja Blokland). Se estamos em mobilidade, também sentimos que o "direito à cidade" (conceito de Henri Lefebvre) passou a ser relido como o "direito à acessibilidade e à mobilidade” (p. 43). Uma vez que passamos a ser móveis nas cidades, novos espaços urbanos também se tornam familiares e novas representações sobre esses mesmos espaços emergem (capítulo 3, de Joan J. Pujadas e Gaspar Maza).

Por outro lado, poderemos ver os espaços urbanos nos quais nos movemos como o resultado das relações sociais numa dada sociedade. Dessa forma, conflitos entre quem exige visibilidade e quem permite essa visibilidade (por exemplo, entre trabalhadores da classe operária e o Estado, através da polícia) emergem nos espaços urbanos, com estes mesmos a serem influenciados por quem consegue impor a sua vontade (capítulo 4, de Ray Hutchison).

Como os espaços urbanos são o resultado das interações sociais entre diferentes grupos, cada grupo social tenta demonstrar o seu "direito à cidade", nomeadamente nos espaços urbanos que são públicos. No entanto, quando vários grupos sociais tentam impor a sua vontade nos usos desses espaços, surgem conflitos, dos quais são exemplo os que ocorreram em 2014, no Brasil, entre moradores, comerciantes e adeptos de futebol em dias de jogo do Campeonato do Mundo de Futebol (capítulo 5, Heitor Frúgoli Jr.).

Voltando ao conceito de "direito à cidade", os responsáveis pelos estabelecimentos comerciais que encontramos nas ruas podem também criar conflitos com potenciais clientes ou com moradores dessas ruas, devido à incompatibilidade de interesses entre quem tenta fazer negócio num determinado setor e quem frequenta/ /vive na zona e preferiria deparar-se com outro tipo de estabelecimento (capítulo 6, de Maxime Felder e Loïc Pignolo).

Por outro lado, as cidades são também marcadas pela insegurança e pela criminalidade, que influenciam as representações que temos delas bem como as nossas deslocações. Tentar perceber que áreas são as mais problemáticas torna-se importante para delimitar estratégias específicas de combate (capítulo 7, de Riccardo Valente). Noutro aspeto relacionado com as cidades, discute-se muito sobre políticas culturais como forma de regeneração urbana. Se estas parecem ser vantajosas na competição entre cidades, fica a dúvida sobre até que ponto promovem a coesão social dos seus habitantes (capítulo 8, de Nunzia Borrelli e Kathleen M. Adams).

Além da mobilidade e da questão do uso do espaço urbano, são ainda abordadas no livro as questões da habitação urbana. Num estudo realizado na Finlândia, tentou perceber-se se existe uma certa perceção de desordem social em bairros construídos após a Segunda Guerra Mundial (capítulo 9, de Teemu Kemppainen). Num outro estudo, realizado na Bósnia-Herzegovina, procurou-se acompanhar o fenómeno das práticas informais de privatização de apartamentos sociais, nomeadamente a sua modificação bem como a apropriação 
de espaços comuns em vários condomínios (capítulo 10, de Sonja Lakić).

Voltando à luta pelo espaço urbano, é dado o exemplo de um conflito emergente nas cidades alemãs: a luta entre projetos de jardinagem em espaços urbanos vazios e grupos sociais que pretendem usar esses espaços para proveito económico (capitulo 11, de Jennifer Morstein). Por fim, usando o caso de Detroit, sobretudo após a declaração de falência da cidade, relata-se o surgimento de projetos de ocupação de espaços livres na cidade que vieram trazer conflitos entre quem pretende colmatar as necessidades das pessoas mais carenciadas e quem defende interesses financeiros emergentes (capítulo 12, de Eve Avdoulos).

Com esta breve síntese é possível verificar que, embora sejam abordadas na obra questões que não são muito recentes (como os capítulos que se baseiam no conceito do "direito à cidade" de Lefebrve), existem outras que são importantes discutir mesmo que não pareçam muito relevantes à primeira vista, como as questões da mobilidade ou da habitação. Estas duas questões, a par da do uso do espaço urbano, oferecem outras perspetivas de entendimento das nossas cidades. Porque, para além de ocuparmos o espaço urbano, também temos necessidade de nos movermos nas cidades e termos os nossos espaços privados, nomeadamente a nossa habitação. Os autores de vários capítulos do livro oferecem, por isso, outras alternativas e visões de olhar as cidades. Regressando ao conceito de "direito à cidade", muito usado e subentendido em alguns dos capítulos aqui referidos, não existe propriamente uma repetição do conceito cunhado por Lefebvre sobre a utilização do espaço urbano pelas classes operárias tendo em vista a reivindicação de direitos. Existe, sim, uma renovação deste conceito à luz dos nossos tempos, ou seja, verifica-se o uso do conceito criado em 1968 em exemplos mais recentes. Poderemos, assim, perceber este conceito, não só aplicado à luta pelos direitos sociais, mas também como forma de reivindicar espaço urbano, que pode ser usado para além dos interesses financeiros de alguns grupos sociais.

Em conclusão, é possível olhar para este livro como sendo um manual atualizado, não só na aplicação do conceito do "direito à cidade”, mas igualmente na chamada de atenção para outras questões urbanas tão relevantes como esta, como a mobilidade e a habitação urbana contemporânea. Podemos entender este livro como um esforço de um grupo de investigadores, que com formações diferentes, mas com interesses de investigação convergentes, apresentam as suas visões sobre as questões urbanas contemporâneas, discutindo-as e apresentando linhas de investigação futuras, uma vez que as cidades não são elementos estáticos e apresentam-se sempre em constante mudança.

Pedro Saraiva

\section{David Castaño}

Instituto Português de Relações Internacionais, Universidade Nova de Lisboa

Rua de D. Estefânia, 195, 5. . D, 1000-155 Lisboa, Portugal

Contacto: davidcastano@fcsh.unl.pt

ORCID: https://orcid.org/0000-0002-8584-8128 


\section{Caio Simões de Araújo}

CISA - Centre for Indian Studies in Africa, University of the Witwatersrand 36 Jorissen Street, Private Bag 3, Wits 2050, Johannesburg, South Africa

Contacto: caio.simoesdearaujo@wits.ac.za

ORCID: https://orcid.org/0000-0002-8502-6263

\section{Antoni Aguiló}

Centro de Estudos Sociais da Universidade de Coimbra

Colégio de S. Jerónimo, Largo D. Dinis, Apartado 3087, 3000-995 Coimbra, Portugal

Contacto: antoniaguilo@ces.uc.pt

ORCID: https://orcid.org/0000-0003-0553-6683

\section{Tânia Regina Krüger}

Departamento de Serviço Social, Universidade Federal de Santa Catarina

Campus Reitor João David Ferreira Lima, s/n, Trindade, CEP 88040-900 Florianópolis,

Santa Catarina, Brasil

Contacto: tania.kruger@ufsc.br

ORCID: https://orcid.org/0000-0002-7122-6088

\section{Edyvar de Mattos Guimarães}

Doutorando em Sociologia Política na Universidade Estadual do Norte Fluminense Darcy Ribeiro Av. Alberto Lamego, 2000, Parque California, Campos dos Goytacazes, Rio de Janeiro,

CEP 28013-602, Brasil

Contacto: guimarvix@hotmail.com

ORCID: https://orcid.org/0000-0001-6495-8347

\section{Pedro Saraiva}

Doutorando na Faculdade de Economia da Universidade de Coimbra I Centro de Estudos Sociais da Universidade de Coimbra

Av. Dr. Dias da Silva, 165, 3004-512 Coimbra, Portugal

Contacto: pdgs@outlook.pt

ORCID: https://orcid.org/0000-0003-0249-2646 
